\title{
Salt-induced and Salt-suppressed Proteins in Tomato Leaves
}

\author{
Suping Zhou ${ }^{1}$ and Roger Sauve \\ School of Agriculture and Consumer Sciences, Tennessee State University, Nashville, TN 37209 \\ Tara Fish and Theodore W. Thannhauser \\ U.S. Department of Agriculture, Agricultural Research Service, 102A R. W. Holley Center for \\ Agriculture \& Health, Cornell University, Ithaca, NY 14853
}

\begin{abstract}
AdDitional INDEX words. proteomics, ferredoxin, NADP (+) reductase, rubisco activase, quinone oxidoreductase, pyrophosphorylase, heat shock, germin, Solanum lycopersicum

Abstract. Tomato (Solanum lycopersicum cv. Money Maker) seedlings at the two-leaf stage were grown in one-half strength Hoagland solution supplemented with $50 \mathrm{~mm} \mathrm{NaCl}$ for 4 days, with $100 \mathrm{~mm} \mathrm{NaCl}$ for 4 days, with $150 \mathrm{~mm}$ $\mathrm{NaCl}$ for 4 days, and with a final concentration $200 \mathrm{~mm} \mathrm{NaCl}$ for 2 days. Solutions were refreshed every 2 days for treated and untreated seedlings. Non-treated plants were grown in nonamended one-half strength Hoagland solution. Three biological replicates (BR) were included for treated and control experiments. At the end of treatments, the uppermost three newly expanded leaves from all 12 plants in each BR were collected and bulked to extract total protein. Proteomic analysis resulted in the identification of several salt-induced and salt-suppressed proteins. Saltinduced proteins were: vacuolar $\mathrm{H}^{+}$-ATPase A1 subunit isoform (1.6-fold), germin-like protein (1.5-fold), ferredoxinNADP $(+)$ reductase $(1.2$-fold), quinone oxidoreductase-like protein (4.4-fold), heat-shock protein (4.9-fold), and pyrophosphorylase (1.7-fold). Salt-suppressed proteins were: ATPase alpha subunit (-1.5-fold) and rubisco activase (-1.4-fold). Proteins identified in this study affect cellular activities for antioxidant, stress protection, carbon fixation, and carbohydrate partitioning in young tomato leaves under salt stress.
\end{abstract}

Soil salinity is a worldwide threat to irrigated vegetable and other crop production. Under saline conditions, the monovalent $\mathrm{Na}^{+}$cation competes mainly with $\mathrm{K}^{+}$due to their similar valance structure, and interferes in normal cellular processes (Fonseca et al., 2007). In addition to being toxic, $\mathrm{NaCl}$ can cause osmotic stress and deficiency of essential nutrient elements (Zhu 2003).

The cultivated tomato is classified as a moderately saltsensitive plant (Katerji et al., 2003). When grown in saline media, tomato production is reduced by $50 \%$ when the saturation extract reaches an electrical conductivity (EC) of $7.5 \mathrm{dS} \cdot \mathrm{m}^{-1}$ (Caro et al., 1991). Physiological studies with different tomato cultivars grown in high salt solutions indicate that $\mathrm{Na}^{+}$ions are transported and accumulated in leaf tissues, and consequently become inhibitory to photosynthetic activities in sensitive genotypes (Dehan and Tal, 1977).

The ability of plants to maintain low cytosolic sodium concentrations is controlled by their ability to selectively absorb $\mathrm{Na}^{+}$and $\mathrm{K}^{+}$by their roots, transport these ions to aboveground tissues, and exclude or compartmentalize $\mathrm{Na}^{+}$in foliar vacuoles. These activities are modulated through the functions of $\mathrm{Na}^{+} / \mathrm{K}^{+}$-ATPase of several transmembrane proteins (transporters and antiporters) and $\mathrm{H}^{+}$pumps (Fonseca et al., 2007; Zhu, 2003). Zhang and Blumwald (2001) found that overexpression of a vacuolar $\mathrm{Na}^{+} / \mathrm{H}^{+}$antiport gene in transgenic

This work was supported by a CSREES-USDA Capacity Building Grant (no. 2005-38814-16424), by ARS CRIS project number 1907-21000-024-00D, and by NSF DBI-0606596.

This manuscript was reviewed by Drs. Chen Fu-Chi and by Myles Elbert at Tennessee State University. We appreciate the assistance of Yong Yang and of Kevin Howe at the Functional and Comparative Proteomics Center, USDAARS Plant, Soil, and Nutrition Laboratory at Cornell University, and of Sarah Bhatti at Tennessee State University.

${ }^{1}$ Corresponding author. E-mail: zsuping@tnstate.edu. tomato enhanced the secretion of $\mathrm{Na}^{+}$into vacuoles, reducing toxic cation concentrations in cytosolic spaces, which allowed these plants to grow, flower, and produce fruits when subjected to $200 \mathrm{~mm}$ sodium chloride. The yeast $H A L 1$ gene facilitates $\mathrm{K}^{+} / \mathrm{Na}^{+}$selectivity and salt tolerance in cells. Under salt stress (100 mM), homozygous transgenic tomato lines overexpressing the $H A L 1$ gene retained more $\mathrm{K}^{+}$than wild types, but it did not improve their salt tolerance in terms of increase in fruit yields (Gisbert et al., 2000; Muñoz-Mayor et al., 2008).

The performance of tomato plants under salt stress is regulated by a complex genetic mechanism (Foolad, 2004). Plants perceive and respond to stressful conditions by quickly altering their gene expression in parallel with physiological and biochemical modulation. To adapt to salt stress, new proteins in tomato seedlings are induced (Amini et al., 2007). To maintain inner cellular osmotic status, tolerant genotypes can accumulate a higher content of inositol and sugars in their leaves (Sacher and Staples, 1985). mRNA profiling of NaCl-treated tomato plants has shown that salt stress can affect many different pathways (Ouyang et al., 2007; Zhou et al., 2007).

The objective of this study was to identify salt-regulated proteins using a comparative analysis between $\mathrm{NaCl}$ treated and non-treated leaves. Based on the putative functions of identified proteins, a molecular mechanism for salt tolerance/ sensitivity is proposed.

\section{Material and Methods}

Plant growth conditions and Salt treatments. 'Money Maker' tomato seeds (Rachel's Supply, Gautier, MS) were surface disinfected by submergence in $2.62 \%$ containing sodium hypochlorite (Dolgencorp, Goodlettsville, TN) for 10 min followed by three washes in sterile double-distilled $\mathrm{H}_{2} \mathrm{O}$. Germinated seeds were planted in sterile perlite and placed in 
an incubator at $25^{\circ} \mathrm{C}$ until one leaf on each seedling emerged (20 d). Six uniform-sized seedlings were then transferred to each of the 12 Styrofoam containers $(20 \times 20 \times 15 \mathrm{~cm})$ for treated and nontreated replicates. Three biological replicates, each consisting of 12 plants growing in two Styrofoam containers, were included for treated and control experiments. These containers were filled with one-half strength Hoagland's nutrient solution (Hoagland and Arnon, 1950) and placed on greenhouse benches under natural light at $25 / 21^{\circ} \mathrm{C}$ (day/night). The nutrient solutions were aerated continuously during the experiment and the levels were adjusted daily and replaced with fresh solution every $2 \mathrm{~d}$. A completely randomized design was used.

Salt treatments were initiated when seedlings in each biological replicate (BR) had two fully expanded leaves. They consisted of maintaining test plants in a hydroponic solution supplemented with increasing $\mathrm{NaCl}$ (Fisher Scientific, Pittsburgh) concentrations for $4 \mathrm{~d}$ with $50 \mathrm{~mm}, 4 \mathrm{~d}$ with $100 \mathrm{~mm}, 4 \mathrm{~d}$ with $150 \mathrm{~mm}$, and for $2 \mathrm{~d}$ with a final concentration of $200 \mathrm{~mm}$. Nontreated (control) plants were grown in one-half strength Hoagland's nutrient solutions. At the end of the treatments, the uppermost three fully expanded leaves were harvested from the 12 plants in each $\mathrm{BR}$, bulked, and frozen in liquid $\mathrm{N}_{2}$. For protein extraction, frozen leaves were ground to a fine powder under liquid $\mathrm{N}_{2}$ and suspended in an extraction buffer $(1: 3, \mathrm{v} / \mathrm{w})$ that consisted of $75 \mathrm{~mm}$ Tris, pH 7.5, $100 \mathrm{~mm}$ DTT, 0.3\% SDS, and $0.1 \%$ protease inhibitor cocktail (Sigma, St. Louis), and were incubated overnight at $4{ }^{\circ} \mathrm{C}$ on a rotary mixer.

Preparation of Protein SAMPles, Protein QuANTIFICATION, AND TWO-DIMENSIONAL FLUORESCENCE DIFFERENCE GEL ELECTROPHORESIS (2D-DIGE) ANALYSIS. To remove cell debris, protein extracts were centrifuged at $15,500 g_{n}$ at $4{ }^{\circ} \mathrm{C}$ for 10 min. Proteins in the supernatant were precipitated overnight in a $20 \%$ trichloroacetic acid (TCA) solution at $20{ }^{\circ} \mathrm{C}$ and were pelleted at $15,500 \mathrm{~g}_{\mathrm{n}}$. Pellets were washed five times in prechilled acetone to remove residual TCA and were air dried at $4{ }^{\circ} \mathrm{C}$. After reconstitution in a $2 \mathrm{D}$ protein rehydration buffer [7 $\mathrm{M}$ urea, $2 \mathrm{M}$ thiourea, and 4\% CHAPS (Sigma) in $25 \mathrm{~mm}$ Tris, $\mathrm{pH}$ 8.6], the concentration of total protein in each sample was quantified using the Bradford protein assay (Bio-Rad, Hercules, CA). Bovine serum albumin ranging in concentrations from 0 to $1 \mathrm{mg} \cdot \mathrm{mL}^{-1}$ was used as the standard (van Noorden et al., 2007).

To allow for detectable differences in CyDye (GE HealthCare, Piscataway, NJ) intensities, each biological repeat was labeled with $\mathrm{Cy} 3$ and Cy5. A dye swap was included in the experimental design to provide a technical replicate and to normalize the differences in dye reactivity. To facilitate gel-togel normalization, a Cy2-labeled internal standard containing equal amounts of protein from all samples was included in each gel. Dye swaps and all possible combinations of pairwise comparisons between samples were included. For the composition of samples in each gel, see Table 1.

Samples used for 2D-DIGE were initially fractionated using a Multiphor II system (GE HealthCare). For this first-dimension separation, immobilized pH gradient IPG strips (GE HealthCare) $24 \mathrm{~cm}$ in length with nonlinear $\mathrm{pH} 3.0$ to 11.0 gradients were used. A total of six gels were run, and each one was loaded with labeled protein from nontreated plants $(50 \mu \mathrm{g})$, treated plants $(50 \mu \mathrm{g})$, and internal standard $(50 \mu \mathrm{g})$ samples $(150 \mu \mathrm{g}$ in total), which were mixed with the IPG strip rehydration buffer (7 M urea, $2 \mathrm{M}$ thiourea, 4\% CHAPS, and $10 \mathrm{~mm}$ DTT, all from Sigma) and 2\% IPG strip buffer (GE HealthCare). Four hundred
Table 1. Composition of protein samples for two-dimensional fluorescence difference gel electrophoresis.

\begin{tabular}{llll}
\hline $\begin{array}{l}\text { Gel } \\
\text { no. }\end{array}$ & \multicolumn{1}{c}{$\mathrm{Cy}^{\mathrm{z}}$} & \multicolumn{1}{c}{ Cy5 $5^{\mathrm{y}}$} & $\mathrm{Cy}^{\mathrm{x}}$ \\
\hline 1 & Salt-treatment replicate 1 & Control replicate 2 & STD $^{\mathrm{w}}$ \\
2 & Salt-treatment replicate 2 & Control replicate 3 & STD \\
3 & Salt-treatment replicate 3 & Control replicate1 & STD \\
4 & Control replicate 1 & Salt-treatment replicate 2 & STD \\
5 & Control replicate 2 & Salt-treatment replicate 3 & STD \\
6 & Control replicate 3 & Salt-treatment replicate 1 & STD \\
\hline
\end{tabular}

zProtein labeled with Cy3 dye.

yProtein labeled with Cy5 dye.

xProtein labeled with Cy2 dye.

winternal standard containing a mixture of equal amount proteins from all salt-treated and control replicates was used in comparison for normalizing between gels.

fifty microliters of this solution was added to each lane of each rehydration tray and left to rehydrate at room temperature for $12 \mathrm{~h}$. Isoelectric focusing (IEF) was carried out at $20^{\circ} \mathrm{C}$ and the voltage was increased from 300 to $3500 \mathrm{~V}$ during a 1.5-h period. The final voltage was set at $3500 \mathrm{~V}$ for $4.5 \mathrm{~h}$. At the end of the IEF run, proteins were reduced and alkylated (Zhang et al., 2003).

Strips were transferred and apposed to $24 \times 21-\mathrm{cm}, 12 \%$ precast SDS-polyacrylamide gels (Jule Biotechnologies, New Haven, CT) and were run on an electrophoresis apparatus (DALT Six, GE Healthcare). The following protocol was used: $16^{\circ} \mathrm{C}$ at $20 \mathrm{~mA}$ for $30 \mathrm{~min}$, then $50 \mathrm{~mA}$ for 5 to $6 \mathrm{~h}$ until the bromophenol blue (BPB) front marker reached the bottom of the gel. For expression analysis, proteins were labeled with $\mathrm{Cy}$ dyes as previously described. Digital gel images were obtained using a laser scanner (Typhoon 9400; GE Healthcare) and raw image files were analyzed using the Progenesis Samespots (Nonlinear Dynamics, Newcastle-upon-Tyne, UK).

Observed protein pIs were calculated using the chart of Immobiline DryStrip $\mathrm{pH} 3-10 \mathrm{NL} 24 \mathrm{cM} \mathrm{pH}$ as function of distance at $20{ }^{\circ} \mathrm{C}$ and $8 \mathrm{M}$ urea (GE Healthcare). The molecular mass was calculated based on the protein migration distance (Rf) calibrated against SDS-PAGE Molecular Weight Standards Broad Range (catalogue no. 161-0317; Bio-Rad). Theoretical mass and pIs were predicted using the tool of PeptideMass (SIB Switzerland, 2007). The protein subjected for query was the tomato unigene when the complete gene sequence was available. When the unigene contained a partial sequence, proteins with the highest identity from other species, such as arabidopsis (Arabidopsis thaliana), tobacco (Nicotiana tobaccum), or potato (Solanum tuberosum), were used.

Protein spots that showed a change of at least 1.2-fold (mean of the six gel replicates) between control and treated samples with $P<0.5$ were selected for digestion and identification by mass spectrometry (MS) analysis. For protein identification, separate picking gels were run. Picking gels were stained with colloidal Coomassie blue (NOVEX CCB staining kit; Invitrogen, Carlsbad, CA) and the protein spots were picked manually.

IN-GEL DIGESTION WITH TRYPSIN. In-gel digestions and tryptic peptide extractions were performed following the protocol of Shevchenko et al. (1996) with slight modifications. Gel pieces were washed and destained using a series of washes with $50 \mu \mathrm{L}$ of water, $50 \mu \mathrm{L}$ of $50 \%$ acetonitrile $/ 50 \%$ (Fisher Scientific), $50 \mathrm{~mm}$ ammonium bicarbonate (Sigma), $\mathrm{pH} \mathrm{7.8,} \mathrm{and} 50 \mu \mathrm{L}$ of 
$100 \%$ acetonitrile. Once samples were completely dried, $0.2 \mu \mathrm{g}$ of modified trypsin (Promega, Madison, WI) in $20 \mu \mathrm{L}$ of $50 \mathrm{~mm}$ ammonium bicarbonate ( $\mathrm{pH} 7.8) / 10 \%$ acetonitrile were added to each tube. Samples were iced for $15 \mathrm{~min}$ and incubated overnight at $37^{\circ} \mathrm{C}$.

The recovered supernatant and remaining peptides were sequentially extracted from the gel using a series of solutions. The first one contained $50 \mu \mathrm{L}$ of $50 \%$ acetonitrile with $2 \%$ formic acid (FA) and the second contained $50 \mu \mathrm{L}$ of $90 \%$ acetonitrile with $0.5 \%$ FA. For each extraction, samples were sonicated for $10 \mathrm{~min}$ before removing the supernatant. Supernatants were combined and dried in a Speedvac (Thermo Savant, Holbrook, NY).

Protein identification by MALDI-TOF-TOF MS. Each sample was reconstituted in $3 \mu \mathrm{L}$ of $50 \%$ acetonitrile (ACN) (Fisher Scientific) with $0.1 \%$ trifluoroacetic acid (TFA) before MS analysis and $1 \mu \mathrm{L}$ was spotted on a MALDI target plate and immediately spotted on top with $0.5 \mu \mathrm{L}$ of saturated matrix $\left[10 \mathrm{mg} \cdot \mathrm{mL}^{-1} \alpha\right.$-CHCA ( $\alpha$-cyano-4-hydroxy cinnamic acid (Sigma)] and recrystallized in 50\% ACN with $0.1 \%$ TFA and $1 \mathrm{~mm}$ ammonium phosphate) and was allowed to completely dry. Samples were then subjected to MALDI-TOF/TOF tandem mass spectrometry (MS/MS) analysis using a 4700 Proteomics Analyzer equipped with TOF-TOF ion optics (Applied Biosystems, Framingham, MA) with 4700 Explorer version 3.5. This instrument was operated in $1 \mathrm{kV}$ reflector positive ion mode and calibrated with a calibration kit (Applied Biosystems) containing a mixture of six standard peptides as a default calibration for spectra acquisition. The laser power was set to 4600 for MS and 5200 for MS/MS with CID off. MS spectra were acquired across the mass range of 800 to 4000 Da with a minimum $\mathrm{S} / \mathrm{N}$ filter at 25 for precursor ion selection. MS/MS spectra were acquired for the 20 most abundant precursor ions with a total accumulation of 2000 laser shots.

The combined MS and MS/MS data were submitted to Mascot 2.2 (Matrix Science, Boston) using GPS Explorer 3.65 for a search against the SGN-annotated database (SOL Genomics Network, 2007). The search parameters allowed for one missed tryptic cleavage, and variable modifications of methionine oxidation and cysteine carboxyamidomethylation. When possible, the known autodigestion products of trypsin were used as internal mass calibrants. Only proteins with a $>95 \%$ confidence interval (CI) are listed as identified.

\section{Results and Discussion}

IDENTIFICATION OF SALT-REgULATED PROTEINS IN TOMATO LEAF TISSUES. Proteome analysis was used to compare leaves of NaCl-treated and nontreated tomato plants. Leaves from all BR were collected and analyzed using DIGE (Table 1). Wellresolved protein spots were selected to compare the amount of protein on 2D gels (pI range of 3-11) (Fig. 1A). Seventeen protein spots that significantly changed (analysis of variance $P \leq 0.05$, Table 2) in response to the salt treatment are shown in Fig. 1B. The change in folds for all significant ones was between -1.4 and 4.9 (Table 2).

Using MS/MS and database search, 10 spots with proteins of known identities were identified from salt-treated leaf proteome (Table 2). Identical proteins were confirmed in the corresponding protein spots (protein spot at the same position in treated and untreated protein 2D gels) of the untreated samples. Several protein spots were not identified because there were no

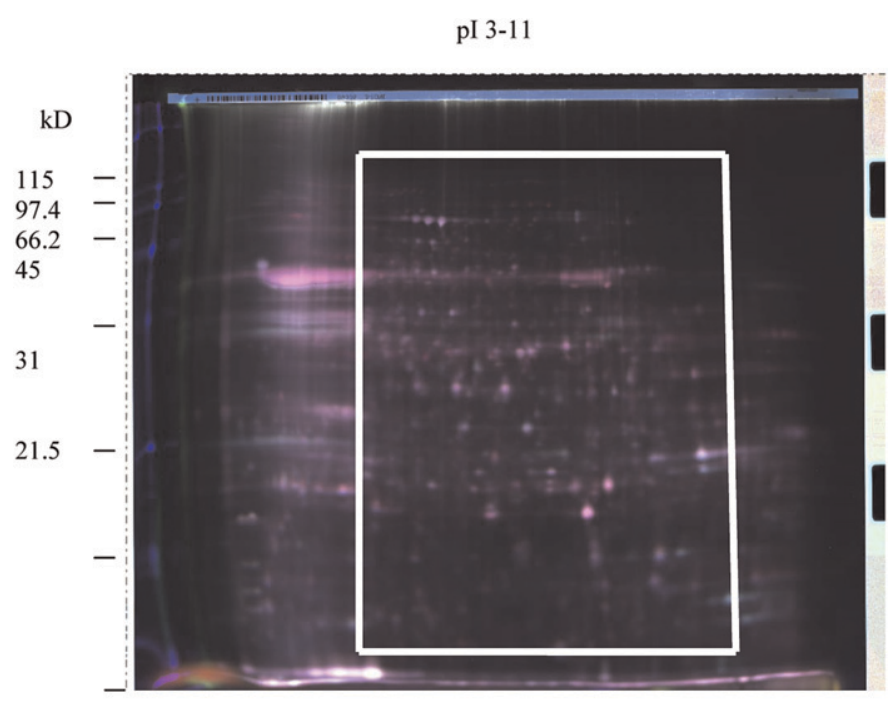

A

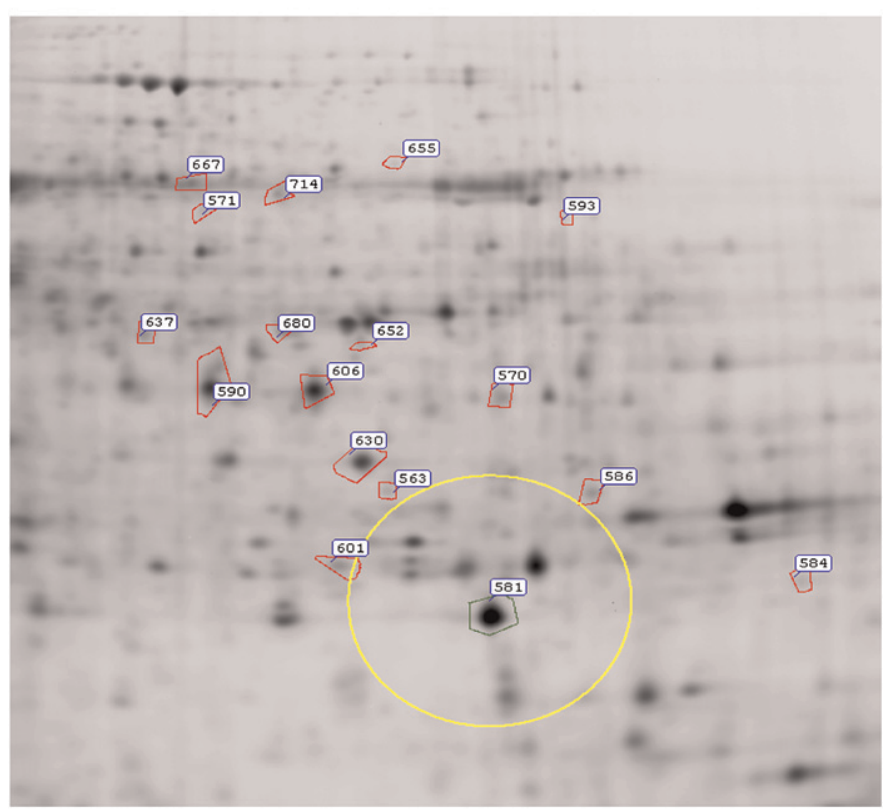

B

Fig. 1. Images for two-dimensional fluorescence difference gel electrophoresis (A) and spot picking gel (B) of tomato leaf protein. Gel (A) shows differential expression of two samples and an internal standard, labeled with Cy3, Cy5, and $\mathrm{Cy} 2$, respectively. Only those well-resolved spots within the heightlighted square were analyzed for protein abundance.

matching proteins in the SGN-annotated database (SOL Genomics Network, 2007).

When compared for the theoretical and observed values of molecular mass and pI of identified proteins, spots 571 and 581 contained the proteins of which both parameters were very similar. However, for other spots, discrepancies between predicted and observed values were observed with the pI, the molecular mass, or both. The proteome is a dynamic system comprising similar proteins with alteration in surface charge or molecular weight that result from post-translational modifications, alternative splicing, etc. (Corthals et al., 2000), and these proteins migrate to different positions on a 2D gel (Marcotte 2001). This could be one of the main reasons that caused the discrepancy between theoretical and observed values. 


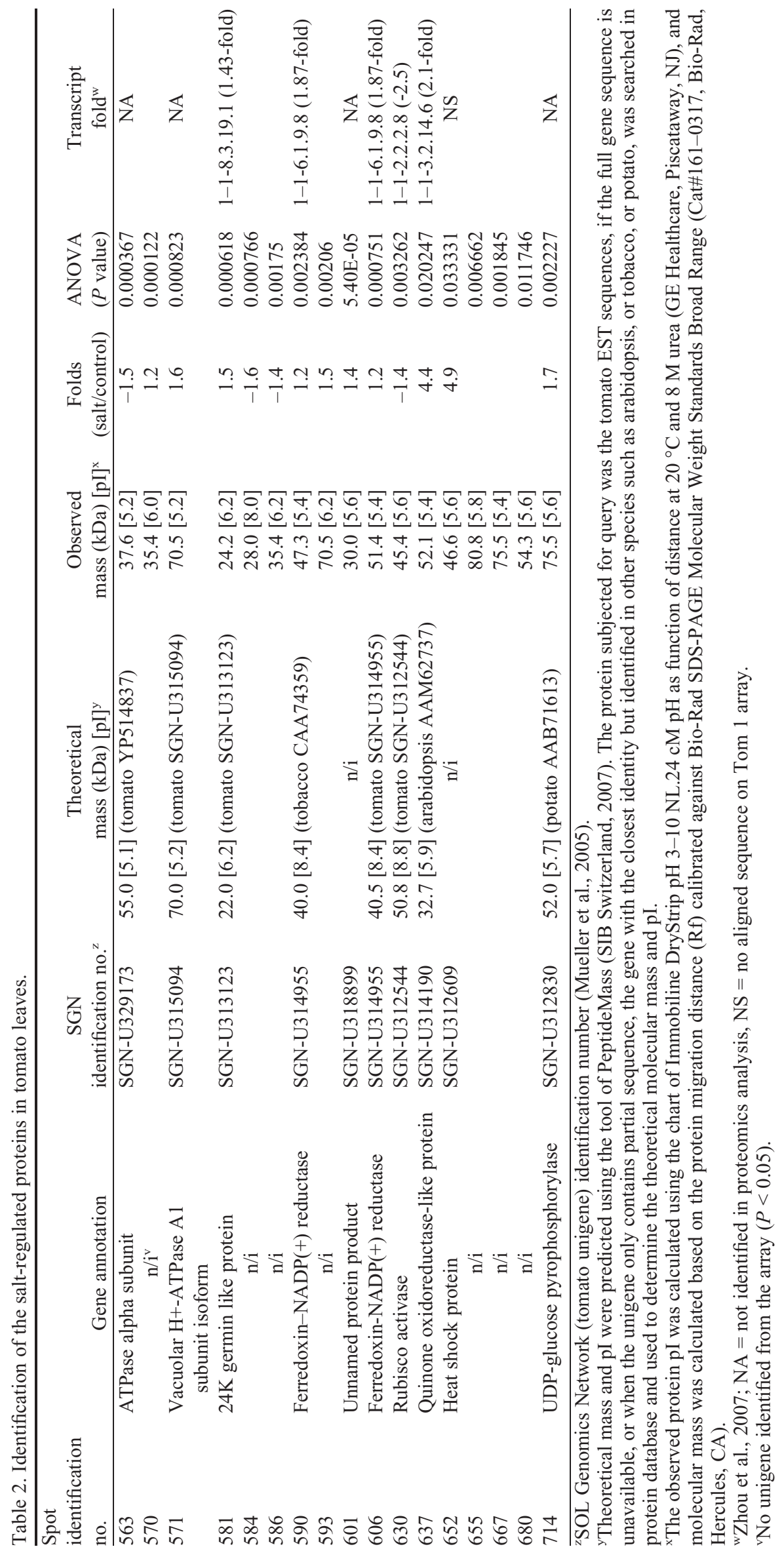


The SGN unigene IDs were cross-linked to the TOM1 cDNA microarray (Boyce Thompson Institute, 2008). When four genes were compared with transcriptional regulation patterns from a microarray analysis (Zhou et al., 2007), they had the same regulatory patterns (up or down) at the protein and transcript levels. These included the induction for the germin protein, ferredoxin-NADP $(+)$ reductase and quinone oxidoreductase-like protein, and the reduction of rubisco activase (Table 2). The expressed sequence tags (ESTs) for other proteins were not found on microarray chips; consequently, their transcriptional activities were not determined.

INDUCTION OF THIOREDOXINS ANTIOXIDANT SYSTEM IN TOMATO LEAVES UNDER SALT STRESS. Maintaining appropriate redox status in cells is important for normal activities. Salt stress induces oxidative stress in chloroplasts and activates different antioxidant mechanisms for defense against injuries (Panda and Upadhyay, 2004; van Camp et al., 1996). The thioredoxin system reduces peroxides such as $\mathrm{H}_{2} \mathrm{O}_{2}$ to harmless products. Plant chloroplastic thioredoxin system uses ferredoxin-dependent thioredoxin reductase, while cytosolic and mitochondrial thioredoxins are reduced by NADPH thioredoxin reductase (Serrato et al., 2004). In leaves of salt-treated tomato plants, the ferredoxin-thioredoxin-reductase protein (SGN-U314955) was induced (1.2-fold). This gene was also induced at the transcript level identified in cDNA microarray analysis [Tom 1 microarray ID: 1-1-7.3.4.5, 1.79-fold (Zhou et al., 2007)].

Salt STRess Suppression of RUbisco ACtivase. Rubisco activase was suppressed at the protein (-1.4-fold) and the transcript ( -2.5 -fold) levels (Table 2$)$. This enzyme is the initial controlling point for carbon fixation because it converts rubisco from an inactive form to an active state and acts as a chaperone for promoting and maintaining catalytic activity (Portis 2003). It also participates in the signal transduction pathway (Komatsu et al., 2003). When enzyme activity between salt-sensitive and selt-tolerant species was compared, rubisco activase was found to be induced by $\mathrm{NaCl}$ in the halotolerant green alga Dunaliella salinaa (Liska et al., 2004) and in the salt-tolerant Populus euphratica (Gu et al., 2004). The overall reduction at transcriptional and translational levels of rubisco activase could lead to lower total enzyme activity and to lower $\mathrm{CO}_{2}$ assimilation in tomato leaves under salt stress.

Salt STRESS induCtion OF QUinONe Detoxification. $\mathrm{NAD}(\mathrm{P}) \mathrm{H}$ :quinone oxidoreductase is an enzyme that detoxifies quinones and their derivatives (Radjendirane et al., 1998; Gaikwad et al., 2001; Schuler et al., 1999). Salt stress induces lipid peroxidation in leaves of sensitive $A$. thaliana (Cavalcanti et al., 2007), producing toxic reactive aldehydes that can be scavenged by the NAD(P)H:quinone oxidoreductase homolog (Mano et al., 2002). NAD(P)H:quinone oxidoreductase has been shown to be responsible for the detoxification of heavy metals in mammalian cells (He et al., 2006; Korashy and ElKadi, 2006). In leaves of salt-treated tomato plants, the quinone oxidoreductase-like protein (SGN-U314190) had the most significant increase (4.4-fold) and concurrently the corresponding EST transcript (1-1-3.2.14.6) also had a 2-fold increase (Zhou et al., 2007).

INDUCTION OF UDP-GLUCOSE PYROPHOSPHORYLASE AND PARTITIONING OF CARBOHYDRATES UNDER SALT STRESS. Salt stresS affects carbohydrate metabolism and partitioning in various organisms (Chen et al. 2006; Fernandes et al., 2004; Khelil et al., 2007). UDP-glucose pyrophosphorylase (UGPase) catalyzes conversion of glucose-1-phosphate and UTP into uridine diphosphoglucose (UDPG), which is a key precursor for the biosynthesis of sucrose (Meng et al., 2007), cell wall polysaccharides (Ordin and Hall, 1968), and starch (Viola et al., 2001). Salt stress enhanced the accumulation of UGPase in tomato leaves by 1.7 -fold (Table 1 ). To determine the dominant partition of UDPG, we compared the transcript level associated with those metabolic reactions (Zhou et al., 2007). Sucrose synthase catalyzes the degradation of sucrose to UDPG in the following reaction: UDP + sucrose $=$ UDPG + fructose. According to transcript changes, salt stress induced the sucrose synthase gene (1-1-8.4.8.6). Sucrose molecules maintain the cellular osmotic equilibrium between the intra- and extracellular environment, protecting cells from osmotic damage. Juan et al. (2005) reported that salt-tolerant tomato cultivars had a sucrose concentration almost twice that of the most sensitive cultivars. In leaves of salt-treated plants, the induction of sucrose synthase could enhance the conversion of sucrose into UDPG; however, its impact on the concentration of sucrose in leaves of salt-treated plants needs to be further studied.

In this study, most of the known genes related to cell wall synthesis were induced; these were: cellulose synthase (1-1-7.4.1.7, 3.25-fold-up), which catalyzes the synthesis of cellulose, the endoxyloglucan transferase (1-1-5.2.13.2, 1.61fold-up), and the lignin-forming anionic peroxidase precursor (1-1-2.4.20.1, 1.68-fold-up). Extensive deposition of secondary cell wall materials prevents cell expansion (Lagrimini et al., 1987). Plant growth in the transgenic hybrid poplar (Populus alba $\times P$. grandidentata) overexpressing a UDP-glucose pyrophosphorylase (UGPase) from Acetobacter xylinum was retarded and accompanied by higher cellulose contents (Coleman et al., 2007). In tomato plants, the pattern of carbohydrate partitioning appears to favor cell wall synthesis. Its impact on young leaf growth needs to be further investigated.

\section{Conclusion}

In leaves of salt-treated tomato plants, ferredoxin-thioredoxin-reductase and quinone oxidoreductase were activated to alleviate oxidative stress and to detoxify toxic molecules generated by the stress. Rubisco activase was suppressed; this could lead to reduction in carbon fixation and glucose synthesis. UDP-glucose pyrophosphorylase was induced, but the UDPG products appeared to be more likely used for the synthesis of cell wall materials instead of sucrose and starch.

\section{Literature Cited}

Amini, A., A. Ehsanpour, Q.T. Hoang, and J.S. Shin. 2007. Protein pattern changes in tomato under in vitro salt stress. Russ. J. Plant Physiol. 54:464-471.

Boyce Thompson Institute. 2008. Tom 1 microarray. 1 July 2008. $<$ http://ted.bti.cornell.edu/cgi-bin/TFGD/array $>$.

Caro, M., V. Cruz, J. Cuartero, M.T. Estan, and M.C. Bolarin. 1991. Salinity tolerance of normal-fruited and cherry tomato cultivars. Plant Soil 136:249-255.

Cavalcanti, F.R., J.P. Lima, S.L. Ferreira-Silva, R.A. Viégas, and J.A. Silveira. 2007. Roots and leaves display contrasting oxidative response during salt stress and recovery in cowpea. J. Plant Physiol. 164:591-600.

Chen, L., D. Li, L. Song, G. Wang, and Y. Liu. 2006. Effects of salt stress on carbohydrate metabolism in desert soil alga Microcoleus vaginatus Gom. J. Integr. Plant Biol. 48:914-919.

Coleman, H.D., T. Canam, K.Y. Kang, D.D. Ellis, and S.D. Mansfield. 2007. Over-expression of UDP-glucose pyrophosphorylase in hybrid poplar affects carbon allocation. J. Expt. Bot. 58:4257-4268. 
Corthals, G.L., V.C. Wasinger, D.F. Hochstrasser, and J.C. Sanchez. 2000. The dynamic range of protein expression: A challenge for proteomic research. Electrophoresis 21:1104-1115.

Dehan, K. and M. Tal. 1977. Salt tolerance in the wild relatives of the cultivated tomato: Responses of Solanum pennellii to high salinity. Irrig. Sci. 1:71-76.

Fernandes, F.M., M.C. Arrabaca, and M.M. Carvalhol. 2004. Sucrose metabolism in Lupinus albus L. under salt stress. Biol. Plant. 48:317-319.

Fonseca, J., S. Kaya, S. Guennoun, and R. Rakowski. 2007. Temporal analysis of valence and electrostatics in ion-motive sodium pump. J. Comput. Electron. 6:381-385.

Foolad, M.R. 2004. Recent advances in genetics of salt tolerance in tomato. Plant Cell Tissue Organ Cult. 76:101-119.

Gaikwad, A., D.J. Long, II, J.L. Stringer, and A.K. Jaywalk. 2001. In vivo role of NAD (P) H: Quinone oxidoreductase 1 (NQO1) in the regulation of intracellular redox state and accumulation of abdominal adipose tissue. J. Biol. Chem. 276:22559-22564.

Gisbert, C., A.M. Rus, M.C. Bolarin, J.M. Lopez-Coronado, I. Arrillaga, C. Montesinos, M. Caro, R. Serrano, and V. Moreno. 2000. The yeast HAL1 gene improves salt tolerance of transgenic tomato. Plant Physiol. 123:393-402.

Gu, R.S., S. Fonseca, L.G. Puskás, L. Jr. Hackler, Á. Zvara, D. Dudits, and M.S. Pais. 2004. Transcript identification and profiling during salt stress and recovery of Populus euphratica. Tree Physiol. 24:265-276.

He, X., M.G. Chen, G.X. Lin, and Q. Ma. 2006. Arsenic induces NAD (P) H-quinone oxidoreductase I by disrupting the Nrf2_Keap1_Cul3 complex and recruitingNrf2_Maf to the antioxidant response element enhancer. J. Biol. Chem. 281:23620-23631.

Hoagland, D.R. and D.I. Arnon. 1950. The water-culture method for growing plants without soil. Univ. California Agr. Expt. Sta. Circ. 347.

Juan, M., R.M. Rivero, L. Romero, and J.M. Ruiz. 2005. Evaluation of some nutritional and biochemical indicators in selecting salt-resistant tomato cultivars. Environ. Exp. Bot. 54:193-201.

Katerji, N., J.W. van Hoorn, A. Hamdy, and M. Mastrorilli. 2003. Salinity effect on crop development and yield, analysis of salt tolerance according to several classification methods. Agr. Water Manage. 62:37-66.

Khelil, A., T. Menu, and B. Ricard. 2007. Adaptive response to salt involving carbohydrate metabolism in leaves of a salt-sensitive tomato cultivar. Plant Physiol. Biochem. 45:551-559.

Komatsu, S., H. Konishi, S. Shen, and G. Yang. 2003. Rice proteomics. A step toward functional analysis of the rice genome. Mol. Cell. Proteomics 2:2-10.

Korashy, H.M. and A.O.S. El-Kadi. 2006. Transcriptional regulation of the NAD (P) H: Quinone oxiductase 1 and glutathione Stransferase YA genes by mercury, lead, and copper. Drug Metab. Dispos. 34:152-165.

Lagrimini, L.M., W. Burkhart, M. Moyer, and S. Rothstein. 1987. Molecular cloning of complementary DNA encoding the ligninforming peroxidase from tobacco: Molecular analysis and tissuespecific expression. Proc. Natl. Acad. Sci. USA 84:7542-7546.

Liska, A.J., A. Shevchenko, U. Pick, and A. Katz. 2004. Enhanced photosynthesis and redox energy production contribute to salinity tolerance in Dunaliella as revealed by homology-based proteomics. Plant Physiol. 136:2806-2817.

Mano, J., Y. Torii, S.-I. Hayashi, K. Takimoto, K. Matsui, K. Nakamura, D. Inzé, E. Babiychuk, S. Kushnir, and K. Asada. 2002. The NADPH: Quinone oxidoreductase P1-crystallin in Arabidopsis catalyzes the $\beta$-hydrogenation of 2-alkenals: Detoxification of the lipid peroxidederived reactive aldehydes. Plant Cell Physiol. 43:1445-1455.

Marcotte, E.M. 2001. Measuring the dynamics of the proteome. Genome Res. 11:191-193.

Meng, M., M. Geisler, M.H. Johansson, E.J. Mellerowicz, S. Karpinski, and L.A. Kleczkowski. 2007. Differential tissue/organ-dependent expression of two sucrose- and cold-responsive genes for UDPglucose pyrophosphorylase in Populus. Gene 389:186-195.
Mueller, L.A., T.H. Solow, N. Taylor, B. Skwarecki, R. Buels, J. Binns, C. Lin, M.H. Wright, R. Ahrens, Y. Wang, E.V. Herbst, E.R. Keyder, N. Menda, D. Zamir, and S.D. Tanksley. 2005. The SOL Genomics Network. A comparative resource for Solanaceae biology and beyond. Plant Physiol. 138:1310-1317.

Muñoz-Mayor, A., B. Pineda, J.O. Garcia-Abellán, B. Garcia-Sogo, E. Moyano, A. Atares, F. Vicente-Agulló, R. Serrano, V. Moreno, and M.C. Bolarin. 2008. The HAL1 function on $\mathrm{Na}^{+}$homeostasis is maintained over time in salt-treated transgenic tomato plants, but the high reduction of $\mathrm{Na}^{+}$in leaf is not associated with salt tolerance. Physiol. Plant. 133:288-297.

Ordin, L. and M.A. Hall. 1968. Cellulose synthesis in higher plants from UDP glucose. Plant Physiol. 43:473-476.

Ouyang, B., T. Yang, H. Li, L. Zhang, Y. Zhang, J. Zhang, Z. Fei, and Z. Ye. 2007. Identification of early salt stress response genes in tomato root by suppression subtractive hybridization and microarray analysis. J. Expt. Bot. 58:507-520.

Panda, S.K. and R.K. Upadhyay. 2004. Salt stress injury induces oxidative alterations and antioxidative defense in the roots of Lemna minor. Biol. Plant. 48:249-253.

Portis A.R., Jr. 2003. Rubisco activase-RUBISCO'S catalytic chaperone. Photosynth. Res. 75:11-27.

Radjendirane, V., P. Joseph, Y.H. Lee, S. Kimura, A.J.P. KleinSazanto, F.J. Gonzalez, and A.K. Jaiswal. 1998. Disruption of the DT diaphorase (NQO1) gene in mice leads to increased menadione toxicity. J. Biol. Chem. 273:7382-7389.

Sacher, R.F. and R.C. Staples. 1985. Inositol and sugars in adaptation of tomato to salt. Plant Physiol. 77:206-210.

Schuler, F., T. Yano, S.D. Bernardo, T. Yagi, V. Yankovskaya, T.P. Singer, and J.E. Casida. 1999. NADH-quinone oxidoreductase: PSST subunit couples electron transfer from iron-sulfur cluster $\mathrm{N}_{2}$ to quinine. Proc. Natl. Acad. Sci. USA 96:4149-4153.

Serrato, A.J., J.M. Pérez-Ruiz, M.C. Spínola, and F.J. Cejudo. 2004. A novel NADPH thioredoxin reductase, localized in the chloroplast, which deficiency causes hypersensitivity to abiotic stress in Arabidopsis thaliana. J. Biol. Chem. 279:43821-43827.

Shevchenko, A., M. Wilm, O. Vorm, and M. Mann. 1996. Mass spectrometric sequencing of protein from silver-stained polyacrylamide gels. Anal. Chem. 68:850-858.

S.I.B. Switzerland. 2007. PeptideMass. 1 July 2009. <http://www.expasy. ch/tools/peptide-mass.html>.

SOL Genomics Network. 2007. Protein predictions for unigene builds. 8 July 2007. <ftp://ftp.sgn.cornell.edu/proteins/>.

van Camp, W., K. Capiau, M. van Montagu, D. Inze, and L. Slooten. 1996. Enhancement of oxidative stress tolerance in transgenic tobacco plants overproducing Fe-superoxide dismutase in chloroplasts. Plant Physiol. 112:1703-1714.

van Noorden, G.E., T. Kerim, N. Goffard, R. Wiblin, F.I. Pellerone, B.G. Rolfe, and U. Mathesius. 2007. Overlap of proteome changes in Medicago truncatula in response to auxin and Sinorhizobium meliloti. Plant Physiol. 144:1115-1131.

Viola, R., P. Nyvall, and M. Pesersén. 2001. The unique features of starch metabolism in red algae. Proc. Royal Soc. London Br. 268: 1417-1422.

Zhang, H.X. and E. Blumwald. 2001. Transgenic salt-tolerant tomato plants accumulate salt in foliage but not in fruit. Nat. Biotechnol. 19: 765-768.

Zhang, S., C.K. Van Pelt, and J.D. Henion. 2003. Automated chipbased nanoelectrospray-mass spectrometry for rapid identification of proteins separated by two-dimensional gel electrophoresis. Electrophoresis 24:3620-3632.

Zhou, S., S. Wei, B. Boone, and S. Levy. 2007. Microarray analysis of genes affected by salt stress in tomato. African J. Environ. Sci. Technol. 1:14-26.

Zhu, J.-K. 2003. Regulation of ion homeostasis under salt stress. Curr. Opin. Plant Biol. 6:441-445. 